\section{Case Reports in Neurology}

Case Rep Neurol 2020;12:460-465

DOI: 10.1159/000510574

Published online: November 27, 2020

(C) 2020 The Author(s)

Published by S. Karger AG, Basel

www.karger.com/crn

This article is licensed under the Creative Commons Attribution-NonCommercial 4.0 International License (CC BY-NC) (http://www.karger.com/Services/OpenAccessLicense).

Usage and distribution for commercial purposes requires written permission.

\title{
Unilateral Dorsolateral Medullary Hemorrhage Presenting with Severe Dysphagia
}

\author{
Fumihito Yoshii $^{a} \quad$ Reiko Matsushita $^{\mathrm{b}}$ Wakoh Takahashic \\ aDepartment of Neurology, Saiseikai Shonan Hiratsuka Hospital, Hiratsuka, Japan; \\ bepartment of Internal Medicine, Saiseikai Shonan Hiratsuka Hospital, Hiratsuka, Japan; \\ 'Department of Neurology, Tokai University Oiso Hospital, Oiso, Japan
}

\section{Keywords}

Medullary hemorrhage $\cdot$ Dysphagia $\cdot$ Wallenberg syndrome

\begin{abstract}
We report an 87-year-old woman with right dorsolateral medullary hemorrhage. She did not show all of the usual symptoms of Wallenberg syndrome and her main symptom was severe dysphagia. Dorsolateral medullary hemorrhage may be overlooked, because it is rare and does not exhibit the typical Wallenberg syndrome presentation usually seen in patients with infarction at the dorsolateral medulla.

(C) 2020 The Author(s) Published by S. Karger AG, Basel
\end{abstract}

\section{Introduction}

Most brainstem hemorrhages occur in the pons, and hemorrhages restricted to the medulla oblongata are very rare. Reported cases with medullary hemorrhage mainly involved arteriovenous malformation rupture, hypertension or hemorrhage extending into the medulla from the pons. Among the few cases of spontaneous medullary hemorrhage in the literature, some were considered to be associated with inadequately controlled anticoagulant therapy [1].

The reason for the low frequency of medullary hemorrhage is unknown, but its rarity may be related to regional anatomical or hemodynamic peculiarities of the perforating arteries at

Fumihito Yoshii
Department of Neurology
Saiseikai Shonan Hiratsuka Hospital
18-1 Miyamatsu-cho, Hiratsuka 254-0036 (Japan)
yoshii@is.icc.u-tokai.ac.jp or fu_yoshii67@yahoo.co.jp




\section{Case Reports in Neurology}

Case Rep Neurol 2020;12:460-465

DOI: $10.1159 / 000510574$

(c) 2020 The Author(s). Published by S. Karger AG, Basel www.karger.com/crn

Yoshii et al.: Unilateral Dorsolateral Medullary Hemorrhage Presenting with Severe Dysphagia

the medulla oblongata [2]. Most medullary perforating arteries run horizontally after leaving the main artery, in contrast to those of the pons. In addition, pathological studies by Cole and Yates [3] suggested that the medullary perforating arteries do not exhibit micro-aneurysms, unlike those of the pons. This difference may explain why primary hemorrhage is less likely at the medulla oblongata.

Here, we describe a patient with unilateral dorsolateral medullary hemorrhage who presented with severe swallowing disturbance as the only major symptom. Although dorsolateral cerebral infarction often shows typical Wallenberg syndrome, this was not observed in our case.

\section{Case Report}

An 87-year-old woman was transferred to the emergency department with mild consciousness cloudiness and swallowing disturbance. She had a history of myocardial infarction 7 years before and had been taking aspirin, isosorbide and lipid-lowering drugs. She had mild, untreated diabetes mellitus. On examination, her consciousness level was 4-4-6 on the Glasgow Coma Scale. Her blood pressure was 128/94 mm Hg and her heart rate was 103/min without arrhythmia. She showed severe dysphagia and hoarseness, but palatal movement and gag reflex were normal and there was no tongue deviation. Except for mild gait ataxia, which was suspected to be of cerebellar origin, no motor or sensory impairment was observed. Bilateral limb tendon reflexes tended to be decreased, but other neurological signs were negative. Blood tests, including a complete blood count, electrolytes, and renal and liver functions were all normal. Fasting glucose level was $170 \mathrm{mg} / \mathrm{dL}$. Chest X-ray and electrocardiogram were noncontributory. Head CT showed a high-density area at the right dorsolateral medulla (Fig. 1a). However, CT angiography performed at the same time did not reveal the cause of the hemorrhagic lesion; there was no aneurysm, cavernous malformation or tumor (Fig. 1b).

After hospitalization, aspirin intake was discontinued, and anti-hypertensive drugs were initiated. Her consciousness level returned to normal within a few days. Due to the swallowing disturbance, nutrition was provided via a feeding tube. Rehabilitation training stabilized her walking and reduced the symptoms of ataxia. She could speak clearly by the 10th hospital day and she was able to take food orally on the 30th hospital day.

The patient underwent 1.5-T MRI scans of the brain on the 8th and 40th hospital days. The 40th day scan still showed a low signal intensity lesion on the right dorsolateral medulla in the T2* sequence image (Fig. 2). MRA conducted at the same time again did not reveal any vascular anomaly or tumor. Diffusion tensor tractography, performed on the same day (40th hospital day) as the second MRI using our previously reported technique [4], showed a decreased volume of the right cortico-mesencephalic tract (Fig. 3).

\section{Discussion}

Neuroimaging studies failed to establish the etiology of the hemorrhage in our patient. In particular, no vascular malformation or small arterial aneurysm was found, though these are now widely accepted to be the genesis of medullary hemorrhage.

Because medullary hemorrhage is rare in the literature, the characteristic symptoms are not well known. Previous reports describe vertigo, nystagmus, dysarthria, nasopharyngeal

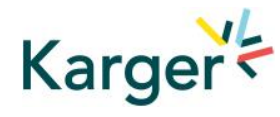




\section{Case Reports in Neurology}

Case Rep Neurol 2020;12:460-465 DOI: $10.1159 / 000510574$

(c) 2020 The Author(s). Published by S. Karger AG, Basel www.karger.com/crn

Yoshii et al.: Unilateral Dorsolateral Medullary Hemorrhage Presenting with Severe Dysphagia

palsy, hypoglossal palsy, cerebellar ataxia, weakness and sensory disturbance corresponding to the location of the hemorrhage [5, 6]. Presumably because sympathetic nerves are abundantly distributed in the medulla oblongata, pulmonary edema [7, 8] or takotsubo cardiomyopathy [9] has also been reported. In our case, although the hemorrhage occurred in the dorsolateral medulla, severe dysphagia was the main symptom. Typical symptoms of Wallenberg syndrome were absent. This seems to be a notable difference between infarction and hemorrhage in the dorsomedial regions.

Swallowing is regulated by a central pattern generator (GCP) located dorsally in the solitary tract nucleus and neighboring medullary reticular formation. The CPG serially activates the cranial nerve motor neurons, including the nucleus ambigus and vagal dorsal motor nucleus. However, the bilateral medullary swallowing centers function as one integrated center, so bilateral lesions of these centers are required to cause complete loss of swallowing [10]. In the present case, the patient had a unilateral hemorrhage and the diffusion tensor tractography clearly showed decreased volume of the right cortico-mesencephalic tract only. These observations suggest that unilateral dorsolateral lesion is enough to cause severe dysphagia. In this case, there was a net regression of dysphagia and the patient was able to eat normally within 2 months, probably because the lesion was unilateral.

\section{Conclusion}

We report a case of dorsolateral medullary hemorrhage, in which dysphagia was the main symptom. In contrast to most patients with infarction, typical signs of Wallenberg syndrome were absent. Thus, medullary hemorrhage needs to be considered in the differential diagnosis of patients with dysphagia.

\section{Acknowledgements}

We thank Mrs. Isa Yoshinari at the Department of Neurology, Saiseikai Shonan Hiratsuka Hospital for her technical assistance.

\section{Statement of Ethics}

The authors hereby declare that all work was conducted in accordance with the Declaration of Helsinki (1964), and the submission of this manuscript for publication has been approved by Saiseikai Shonan Hiratsuka Hospital.

The patient was informed of the purpose of the case presentation and gave her written informed consent to publish her case (including publication of images).

\section{Conflicts of Interest Statement}

The authors declare that there is no conflict of interest regarding the publication of this article.

\section{Karger'"}




\section{Case Reports in Neurology}

\begin{tabular}{l|l}
\hline Case Rep Neurol 2020;12:460-465 \\
\hline DOI: 10.1159/000510574 & $\begin{array}{l}\text { (c) 2020 The Author(s). Published by S. Karger AG, Basel } \\
\text { www.karger.com/crn }\end{array}$ \\
\hline
\end{tabular}

Yoshii et al.: Unilateral Dorsolateral Medullary Hemorrhage Presenting with Severe Dysphagia

\section{Funding Sources}

This case report was not supported by any specific grant from funding agencies in the public, commercial, or non-profit sectors.

\section{Author Contributions}

Fumihito Yoshii, MD: (the principal researcher) examined the patient, contributed to data collection, interpretation and wrote the manuscript.

Reiko Matsushita, MD: examined the patient together with Dr. Yoshii and reviewed the manuscript.

Wakoh Takahashi, MD: reviewed the manuscript.

\section{References}

1 Weisberg LA, Trufant S, Carballosa R, Szanto E. Primary medullary hemorrhage. Comput Med Imaging Graph. 1989 Nov-Dec;13(6):487-90.

2 Mutlu N, Berry RG, Alpers BJ. Massive cerebral hemorrhage. Clinical and pathological correlations. Arch Neurol. 1963 Jun;8(6):644-61.

3 Cole FM, Yates PO. The occurrence and significance of intracerebral micro-aneurysms. J Pathol Bacteriol. 1967 Apr;93(2):393-411.

4 Yoshii F, Tomori Y, Mori T. Diffusion tensor imaging in a case of pontine bleeding showing hypertrophic olivary degeneration and cerebellar ataxia. Case Rep Neurol. 2018 Oct;10(3):297-301.

5 Barinagarrementeria F, Cantú C. Primary medullary hemorrhage. Report of four cases and review of the literature. Stroke. 1994 Aug;25(8):1684-7.

6 Lee SU, Kim HJ, Kang BS, Kim JS. Isolated medullary hemorrhage: clinical features in eleven consecutive patients. J Stroke. 2017 Jan;19(1):111-4.

7 Inobe JJ, Mori T, Ueyama $\mathrm{H}$, Kumamoto $\mathrm{T}$, Tsuda T. Neurogenic pulmonary edema induced by primary medullary hemorrhage: a case report. J Neurol Sci. 2000 Jan;172(1):73-6.

8 Yagi R, Nishimoto Y, Yamada S, Nakashima H, Okada K, Konoeda F, et al. Two medullary hemorrhage cases complicated by respiratory distress in the early phase. J Stroke Cerebrovasc Dis. 2019 Jan;28(1):229-31.

9 Gobeske KT, Sarano ME, Fugate JE, Wijdicks EF. Medulla oblongata hemorrhage and reverse takotsubo cardiomyopathy. Neurocrit Care. 2018 Dec;29(3):508-11.

10 Vigderman AM, Chavin JM, Kososky C, Tahmoush AJ. Aphagia due to pharyngeal constrictor paresis from acute lateral medullary infarction. J Neurol Sci. 1998;155(2):208-10. 
Case Reports in Neurology

\begin{tabular}{l|l}
\hline Case Rep Neurol 2020;12:460-465 \\
\hline DOI: 10.1159/000510574 & $\begin{array}{l}\text { @ 2020 The Author(s). Published by S. Karger AG, Basel } \\
\text { www.karger.com/crn }\end{array}$ \\
\hline
\end{tabular}

Yoshii et al.: Unilateral Dorsolateral Medullary Hemorrhage Presenting with Severe Dysphagia
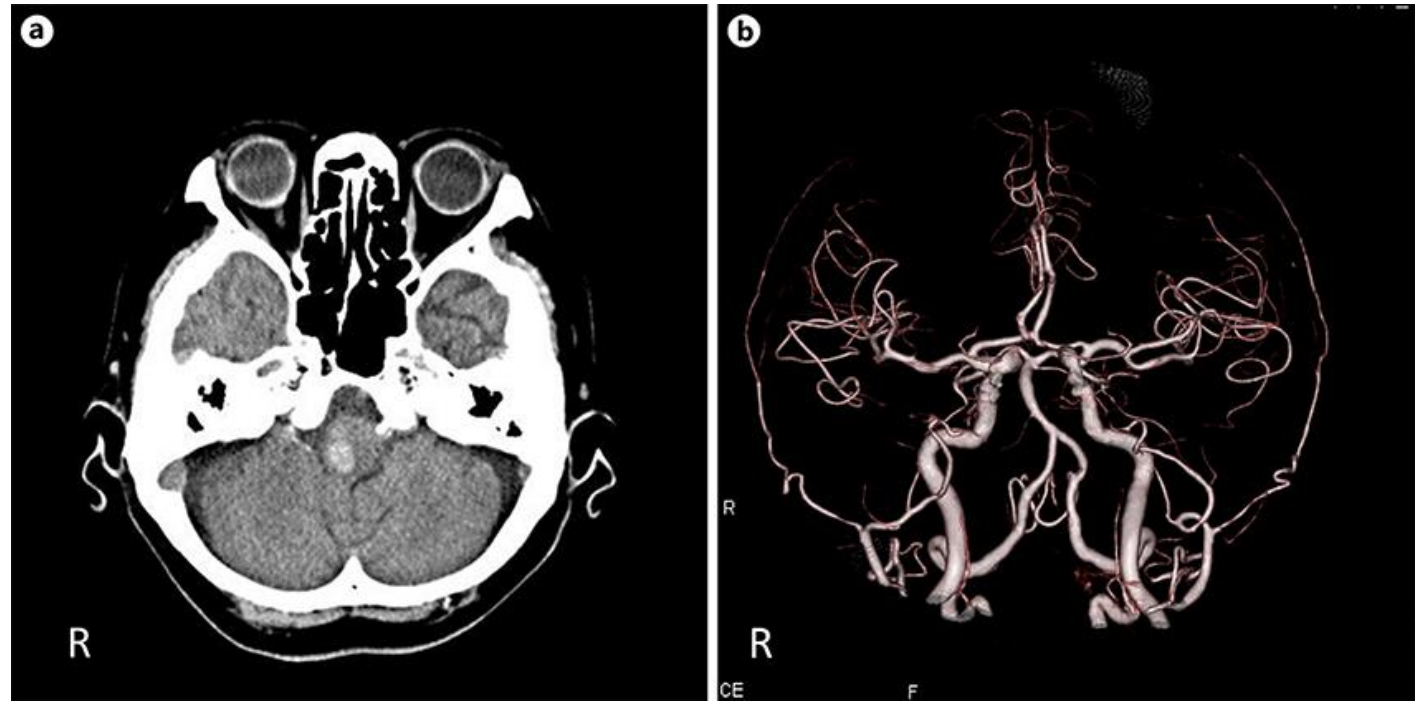

Fig. 1. a Head CT showing high-density area at the right dorsolateral medulla. b CT angiography performed on the same day did not reveal any cause of the hemorrhagic lesion.

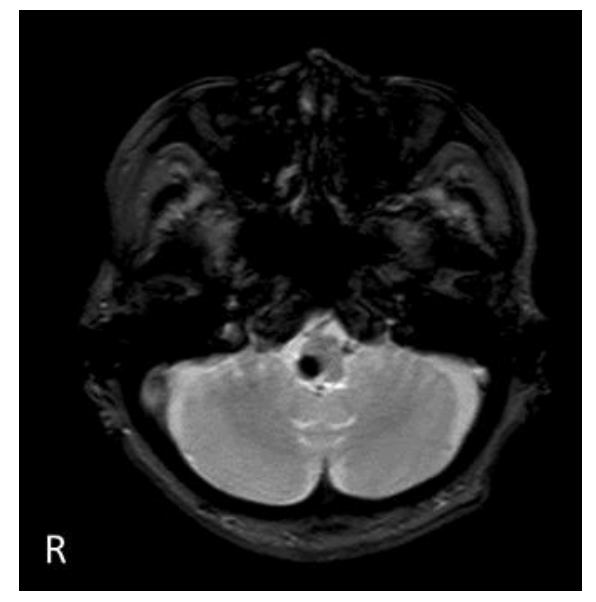

Fig. 2. MRI with $\mathrm{T} 2 *$ sequence showing low signal intensity lesion in the right dorsolateral medulla.

\section{Karger'}


Case Reports in Neurology
Case Rep Neurol 2020;12:460-465

DOI: $10.1159 / 000510574$

(c) 2020 The Author(s). Published by S. Karger AG, Basel www.karger.com/crn

Yoshii et al.: Unilateral Dorsolateral Medullary Hemorrhage Presenting with Severe Dysphagia

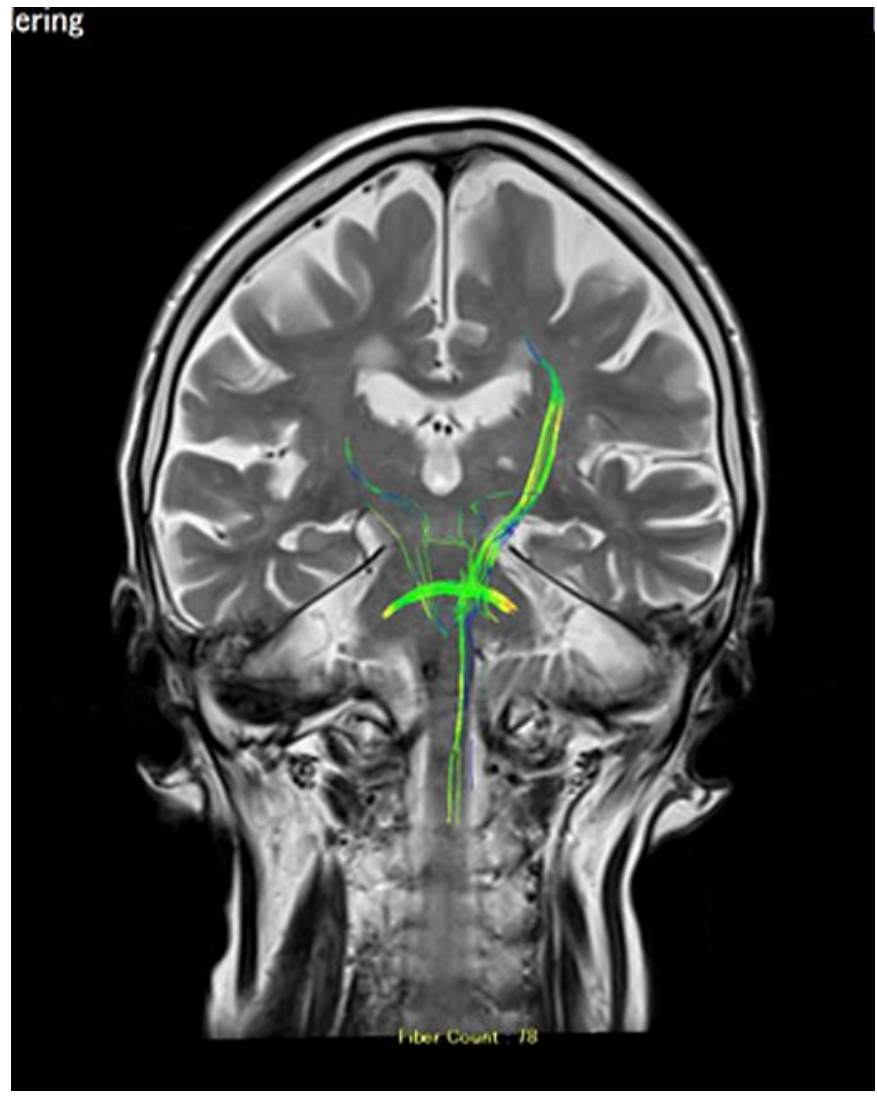

Fig. 3. Diffusion tensor tractography showed a decreased volume of the right cortico-mesencephalic tract. 